\title{
"Ten Major Relations" to Be Addressed for High-Quality Development of Scientific and Technological Innovation
}

\author{
Fanhua Zeng1,2,3, Yangfen $\mathrm{Wu}^{4 *}$, Weichiao Huang5, Peng Luo ${ }^{5}$ \\ ${ }^{1}$ Faculty of Economics and Management, City College, Wuhan University of Science and Technology, Wuhan, China \\ ${ }^{2}$ High Quality Development of Science and Technology Innovation Research Center of Hubei Province, Wuhan, China \\ ${ }^{3}$ School of Economics, Zhongnan University of Economics and Law, Wuhan, China \\ ${ }^{4}$ Marxism College of Wuhan Polytechnic University, Wuhan, China \\ ${ }^{5}$ Department of Economics, Western Michigan University, Kalamazoo, Michigan, USA

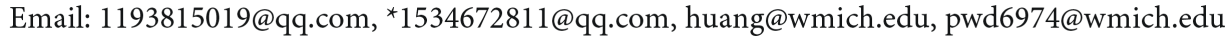

How to cite this paper: Zeng, F. H., Wu, Y. F., Huang, W. C., \& Luo, P. (2020). "Ten Major Relations" to Be Addressed for High-Quality Development of Scientific and Technological Innovation. Modern Economy, 11, 1209-1225.

https://doi.org/10.4236/me.2020.117087

Received: May 6, 2020

Accepted: July 10, 2020

Published: July 13, 2020

Copyright $\odot 2020$ by author(s) and Scientific Research Publishing Inc. This work is licensed under the Creative Commons Attribution International License (CC BY 4.0).

http://creativecommons.org/licenses/by/4.0/

\begin{abstract}
In light of the new era, the main contradictions between China's economic and social operations still rest on the supply side, and with structural characteristics. This article takes the primary contradiction in the supply side of scientific and technological innovation as the logical starting point of analysis. This supply side contradiction refers to the insufficient effective supply of scientific and technological innovation to meet the growing demand for scientific and technological innovation results. We discuss "Ten Major Relations" that need to be addressed to reconcile such contradictions in the supply side of scientific and technological innovation. We then offer a reform path to solve the economic and societal structural conflicts with high-quality science-tech supply.
\end{abstract}

\section{Keywords}

Science-Tech Innovation Supply Side, High-Quality Science and Technology Supply, Major Contradictions, Ten Major Relationships

\section{Introduction}

Recently, there have been various proclamations by Chinese government agencies to promote scientific and technological innovations, including China State Council's 2016 "Outline of National Innovation-Driven Development Strategy" putting forward the strategic goal of "three steps" in the development of scientific and technological innovation; the "19th National Congress" report stating that "in the high-quality development stage of the economy, we must adhere to 
quality, and efficiency first ... to promote reforms in economic development"; and the Ministry of Science and Technology's Opinions in 2018 on "Accelerating the Construction of an Innovative Country" proposing to "Take the promotion of scientific and technological innovation capabilities as the core and systematically improve the overall efficiency of the national innovation system". Further, General Secretary Xi Jinping (2018) emphasized at the Chinese Academy of Sciences in May 2018 that "we must fully understand that innovation is the primary driving force behind high-quality scientific and technological development, and the construction of a modern economic system."

As the main contradiction in China has shifted from insufficient supply production versus people's growing material demand to unequal and inadequate development versus people's growing demand for better quality of life, policymakers' management has also shifted to the track centering on "quality" and "effectiveness". In economic terms, the so-called imbalanced and inadequate development essentially refers to imbalanced and inadequate supply to meet people's need for better life, and the so-called "quality" and "effectiveness" are the "intrinsic power" and "vigor" needed for balanced and high-quality development of the economy, that is, the sufficient provision and supply of scientific and technological innovations. It can be said that the change in the main contradictions of Chinese society is essentially a process that the supply and demand system changes from quantity contradiction to structural contradiction, and also a process in which China's economy changes from a high-speed growth stage to a sustainable growth stage, and the growth momentum changes from production factors-driven to scientific and technological innovation-driven mode. To deal with these changes and the associated consequences and problems, it is imperative to put economic restructuring in the first and foremost front of undertakings. As stated by $\mathrm{Xi}$, "it is necessary to focus on improving the quality and efficiency of development, and to support structural reform on the supply side. The only path to significantly enhance China's economic development quality is through improvement of the quality of the supply system, which hinges on scientific and technological innovations."

Following and drawing from Zeng and $\mathrm{Wu}(2020),{ }^{1}$ this article is based on the principle that contradictions are the driving force for development. This paper uses the main contradictions in the supply side of science and technology innovation as the starting point of analysis. In the framework of supply and demand, we discuss the "Ten Relations" that need to be addressed for high-quality development of scientific and technological innovations.

\section{The Main Contradictions in the Supply Side of Technological Innovation and Their Manifestations}

Zeng and $\mathrm{Wu}$ (2020) identify that parallel to the main contradictions in Chinese ${ }^{1}$ Zeng F. and Y. Wu. "Policy Prescriptions to Achieve High Quality Development of the Supply Side of Scientific and Technological Innovation", Journal of Yunnan University of Finance and Economics, No. 3, 2020, pages 11-19. 
society, the current major contradictions on the supply side of science and technology innovation in China are concentrated in the form of "the growing demand for effective scientific and technological innovation results exceeding the insufficient supply capacity, that is, the contradiction between the demand for technological innovation in economic and social development versus the imbalanced and insufficient development of its supply." Unbalanced and inadequate development of science and technology innovation, on the one hand, refers to the current state of uneven development between supply and demand of science and technology innovation, and on the other hand, refers to the insufficient supply of effective science and technology innovations associated with independent intellectual property rights. This contradiction is mainly manifested in: 1) insufficient original research accomplishments, which are far from meeting the required minimum standards to qualify as an innovative nation; 2) the shortage of key core technologies and high-end technical equipment, and also serious problem of high degree of external dependence; 3 ) the low rate of industrialization and commercialization of scientific and technological achievements, and the lack of synergy between technology and economy; 4) The continuing limitations and resistances to effective science and technology management.

While China's supply quantity of scientific and technological innovations seems to be considerable ${ }^{2}$, the structure and quality of such innovations are not satisfactory. The problem of imbalance between supply and demand of innovations is still very prominent. As China enters the stage of high-quality sustainable development, its scientific and technological innovation supply system is clearly inept to adapt to new changes in economic growth demand. In May 2016, General Secretary Xi Jinping emphasized at the National Science and Technology Innovation Conference that "we must strengthen the supply of science and technology to support economic and social development". In May 2018, Secretary Xi further emphasized at the joint conference of national academies that it is necessary to "fully recognize that innovation is the first driving force, provide high-quality technology supply, ... take improving the quality of supply system as the main path, ... meet real and potential demand, and realize supply-demand matching and dynamic balanced development."

In the past 40 years of economic reform and opening up, China has benefited from advanced industrial countries' sharing of their scientific and technological innovation achievements. Most of the technologies used by domestic enterprises and new products developed are based on the advanced technologies from abroad. This [importation $\rightarrow$ imitation $\rightarrow$ adaptation] innovation path helps China successfully achieve the goal of "catch-up innovation". However, as China's scientific and technological innovation enters the new stage of "running from behind, running side by side, and running ahead and leading", it requires the "hard work" on cutting-edge and original innovation, that is, to solve the ${ }^{2}$ Yangfen Wu, Fanhua Zeng (2019): On the supply side structural reform of scientific and technological innovation based on the perspective of the effective supply hypothesis [J]. Journal of Jiangxi Normal University (Philosophy and Social Sciences Edition), 2019(2), p.124. 
problems of core technology dependence and insufficient supply of high quality and original science and technology.

\section{3. "Ten Major Relations" That Need to Be Addressed for High-Quality Development of Scientific and Technological Innovation}

In order to solve the current supply side problems of China's science and technology innovation, and to improve the quality of its supply system, Zeng and $\mathrm{Wu}$ (2020) provide some insightful prescriptions to China's policy makers. According to them, it is crucial for policymakers to address the following relations.

1) The relationship between various entities involved in collaborative innovation activities

Science and technology innovation activities are interaction processes of various innovation entities. Governments, enterprises, colleges and universities, research institutes, financial institutions, science and technology intermediaries, and end-users (hereinafter abbreviated as Gov, Ent, Aca, Rea, Fin, Int, Use) are interconnected through the chains of institution, policy, industry, knowledge, human resource, technology, capital, and demand. These entities are engaged in multiple forms of collaborative innovation, striving to form a beneficial cycle of converting knowledge into productivity, and to promote the coordinated development of scientific and technological innovation systems. Each of these seven major innovation entities functions differently and plays an important role in science and technology innovation activities. The prerequisite for an effective system integration and coordination of scientific and technological innovation activities is to clarify and delineate the specific role and task for each entity.

Generally, "Ent, Aca, and Rea" forms the axis of the entire collaborative innovation system; "Gov, Fin, and Int" provide services to the former three entities; and "End-user" is the starting point and target point for the sustainable development of the entire "collaborative innovation" system. Specifically, colleges and universities are the main entity of knowledge innovation and talent training in scientific and technological innovation activities, and mainly responsible for basic research tasks. Research institutes collaborate with higher education institutions to conduct creative research, technological innovation, and market-based product development, and mainly responsible for applied research tasks. Enterprises rely on the results of applied research to create new technologies, methods and products, and mainly responsible for development research tasks. The government provides institutional support of the collaborative innovation system and coordinates scientific and technological R \& D activities undertaken by the above entities. Financial institutions create a good funding environment for enterprises to conduct research and development, and provide security and insurance against innovation risks, and mainly responsible for financial support and risk management and guarantee functions. Technology intermediaries are active between technology demanders and suppliers, and mainly responsible for connecting the universities, research institutes and enterprises to provide interme- 
diary services and value-added services for technology exchange, technology transfer and product marketization. The end-users participate in new transformation of the innovation model from "production-centered" to "user-centered" mode. The end-users can, based on their consumption need, modify the direction of innovations, and mainly assume the task and role of "supervising" innovation. These seven major innovation entities in the collaborative innovation system work together to promote the connection between scientific and technological innovation activities and the external market, and ultimately form the largest synergy in the effective supply capacity of scientific and technological innovation.

\section{2) The relationship between independent and imitation innovation}

It is of great significance to correctly handle the relationship between independent innovation and the imported imitation innovation. Introduction and adoption of technology, as an improved imitation innovation, is the main means of technological progress and technology catch-up for developing countries. In the early stage of development, "developing (or behind) countries" often face weak R \& D capabilities and insufficient funding problem, imitating innovation, with the feature of low investment, low risk, and strong market adaptability, has become a natural strategic choice for enterprises to quickly realize capital accumulation and R \& D capabilities. However, when developing countries are impacted by new technology from developed countries which have advantage in independent innovation, they often fall into the disadvantaged cycle of technological dependence. Developing countries will also have to overcome the "bilateral monopoly" trap of technical and market barriers imposed by developed countries, and face a myriad of law and institutional obstacles.

In the 40 years of economic reform and opening up, a large number of Chinese industries, especially emerging industries, have been driven by foreign technology introduction and imitation innovation. However, the long-term emphasis on foreign technology introduction rather than original development has caused domestic industries to lose the control of core technology. The "path dependence" formed by heavy reliance on technology introduction and imitation innovation has greatly inhibited the enterprises' enthusiasm of independent $\mathrm{R} \& \mathrm{D}$ and independent innovation, and has left a big gap in the core technology and high-end cutting-edge technology. As China strives to shift from traditional factor-driven growth to innovation-driven growth, technological innovation has increasingly become a decisive factor for high quality economic development and national competitiveness, and independent innovation has increasingly become the focus of national science and technology innovation development. Generally speaking, there are two ways for China to promote independent innovation: one is to invest less in technology introduction and imitation innovation, and to invest more in independent innovation; the other is to invest and develop more on "improved" imitation innovation, and on independent innovation step by step. The latter approach is usually more conducive to deepening the development of independent innovation. Therefore, the country must not ignore the 
importance of introduction and imitation innovation in the process of emphasizing more on the development of independent innovation. Accelerating the pace of independent innovation by imitation innovation is the correct method to efficiently realize the development of a country powerful in science and technology.

\section{3) Relationship between basic research and applied research}

As China's total investment in scientific research and technology level are gradually approaching the world top level, the investment emphasis and preference toward basic research or applied research will, to a large extent, determine the contribution of scientific research to innovation growth ${ }^{3}$. During China's past 40 years of rapid economic growth, the proportion of applied research in GDP has continued to be higher than that of basic research. Applied research has played a more significant role in driving economic growth than basic research. According to "2017 National Science and Technology Fund Investment Statistics Bulletin" jointly issued by National Bureau of Statistics, Ministry of Science and Technology and Ministry of Finance in October 2018, China's basic research funding in 2017 was 97.55 billion yuan, an increase of 15.26 billion yuan over the previous year; and accounting for only $5.5 \%$ of the total R \& D funding. There is still a large gap compared with the corresponding proportion of about $15 \%$ in developed countries.

Basic research, as the cornerstone of scientific and technological innovation, is the source of nurturing sophisticated and cutting-edge technological innovation capabilities, and is the cradle for cultivating advanced scientific and technological innovation talents. The more solid the basic research skills are developed, the smoother the transformation of scientific and technological achievements into applied productive capability. Once great breakthroughs are made in basic research, the entire country's scientific and technological and social productivity will surely achieve quantum leap advances. As China's economy is moving from a high-speed growth stage to a high-quality development stage, the past strategy of emphasizing applied research needs to be adjusted to focus more on basic and original research. "A country that depends on other nations in basic scientific knowledge will have slow industrial progress, and will have weak competitive position in world trade ${ }^{4}$. Developed countries with leading technological advantages will not transfer their leading edge technologies to other countries. Those countries that have not established a systematic basic research system are mostly incapable to escape the passive and disadvantaged position in international trade and competition. In this regard, General Secretary Xi Jinping urged the academicians in the annual joint meetings of the two academies in 2018: "We must aim to attain the forefront of the world's science and technology, play a good 'first move', lay a solid foundation to realize major breakthroughs in for${ }^{3}$ Zao Sun, Xuelu Xu: The cutting-edge technology gap and the innovative effects of scientific research: Basic research versus applied research, which plays a more important role? [J]. China Industrial Economy, 2017 (03): 5-23.

${ }^{4}$ Vannevar Bush. Science: The endless Frontier, 2004, p. 64. 
ward-looking basic and original research achievements."

Moreover, with the advent of the knowledge economy era, the product update rate continues to accelerate, and the innovation cycle is getting shorter and shorter. With the rising trend of cross-penetration, mutual complementarity, and side-by-side cooperation between traditional basic research and applied research, it is crucial strategically to ride with the mainstream trend to direct applied research effort toward basic research in scientific and technological research and development activities.

\section{4) The relationship between talent-driven and innovation-driven}

Regarding the relationship between talent-driven and innovation-driven, China's policy orientation is increasingly clear with consensus that innovation is the first driving force for development, and talent is the first and foremost resource of innovation. General Secretary Xi pointed out at the 2018 annual joint meetings of Chinese Academy of Sciences and Chinese Academy of Social Sciences that the relationship between "talent-driven" and "innovation-driven" is that "The essence of innovation-driven is talent-driven". He stressed that the strategy to succeed in high-quality development is to focus on becoming an innovation-driven economy, and to achieve that requires putting the issue of talents at the core and the most fundamental strategic position.

The key of innovation is attraction of human capital. As science and technology capacity becomes more and more a decisive factor in the competitiveness of economic and national strength, innovative talents have become the most important strategic resource for countries in the era of knowledge economy. Cultivating, attracting and retaining innovative talents have therefore become the basic strategic guideline for countries to seize the commanding heights of economic development and international competition. Several initiatives and measures need to be implemented to train, nurture and attract scientific and technological talents, including: improving the scientific and technological talent development institutions and environment, formulating high-quality talent training and attraction policies that are in line with national conditions and priorities, and reforming (removing) unreasonable talent evaluation and reward management mechanisms, etc. Policies need to be formulated to break unnecessary institutional barriers, improve the construction of scientific research platforms and innovation bases, and allow innovative talents to flow freely across universities, research institutes, enterprises and even global markets. Only by forming the team of world-class scientific and technological talent pools can China generate world-class innovation results and become the frontrunner and leader of the world's innovation trend. At a time when China's scientific and technological innovation is striving to leap from quantitative accumulation to qualitative breakthrough, from single point breakthrough to extensive system capacity improvement, it is more urgent than ever to "Widely open the road to advancement, and accept the talents all over the globe."

5) The relationship between government guidance and corporate innovation autonomy 
The government's support for scientific and technological innovation activities runs through the entire process of basic research, applied research, development research, and even production and sales. Government support is an important force to promote scientific and technological innovation network links and has a significant impact on the efficiency of scientific and technological innovation. However, as contended by Ye and Liu (2018), it is important to recognize and reconcile the role of government and enterprises in scientific and technological innovation activities. They provide theoretical and empirical analysis on why China's scientific and technological innovation activities have not succeeded in transforming economic growth from factor-driven to innovation-driven pattern, and instead generated a suppression effect. Ye and Liu (2018) find that, on the one hand, increased investment in development research has a significant inhibitory effect on economic growth driven by increase in total factor productivity. Increasing investment in scientific research (including basic research and applied research) has no direct impact on total factor productivity in the short term. On the other hand, the government's emphasis on scientific research investment in the long run will help drive scientific and technological innovation and development. Nonetheless, government should still support development research, but need to do it in moderation to mitigate its inhibitory effect on total factor productivity from excessive investment in development research ${ }^{5}$.

Scientific research is often directly related to the lifeblood of a country's economic development and international status. Given its importance government should not relax its strong support for scientific research at any time. However, because scientific research activities are generally characterized by large start-up investment and inputs, long cycles, strong uncertainty, and significant externalities, their positive output effects are usually not significant in the short term, and may even show negative inhibiting effects on output. Therefore, enterprises often have neither ability nor incentive to invest in basic scientific research, which can only be led and supported by the government. In contrast to basic scientific research, technology development or applied research is characterized by less start-up investment required, short cycle, and less uncertainty, and products developed can be marketed to generate ready returns. Consequently most companies driven by the market profit maximization incentive mechanism are willing to engage in development research. To mitigate market risks and technological risks still exist in development research, the government can also provide enterprises appropriate support and guidance to help stimulate the autonomous enterprises to take initiative undertaking corporate innovations.

Clearly, the government has different function and role to play in basic scientific research and development research, the two different types of scientific and technological innovation activities. Therefore, while the state is pursuing a strategy of increasing and strengthening investment in science and technology ${ }^{5}$ Songsong Ye, Jing Liu (2018): Heterogeneous R \& D, government support, and economic research on China's science and technology innovation dilemma, Economic Research, 2018 (09): 116-132. 
research and development, it must pay attention to handling the relationship between government support and enterprise autonomy. At present, it is necessary to appropriately adjust the ratio of governmental support between basic scientific research and development research, and shift more towards scientific research. At the same time, government can still moderately guide and support development research, while appropriately reduce its support of technology development research. Doing so not only can alleviate the dilemma that increased national research and experimental funding inhibits the contribution of total factor productivity to economic growth, but also can control key technologies and cutting-edge technologies in its own hand so as to cope with and avoid various challenges similar to recent China-US trade frictions.

\section{6) Relationship between innovation chain and industry chain}

The innovation chain and industrial chain are different from each other but mutually reinforcing. On the one hand, innovation chain is the source and foundation of the formation and development of industrial chain. On the other hand, industrial chain is the extension and development of innovation chain. Innovation-driven high-quality economic development can only be achieved with the support coming from the industrial chain, and cannot be achieved by simply emphasizing the development of innovation chain alone or by decoupling the development of innovation chain from industrial chain. In 2015, General Secretary Xi emphasized at the Ninth National Congress that "the system obstacles must be removed, and the innovation chain must be deployed around industrial chain to eliminate the "island phenomenon" in technological innovation". In 2018, at the annual joint conference of the two academies, General Secretary $\mathrm{Xi}$ again emphasized "the need to promote precise docking of the innovation chain and industrial chain, to accelerate the transformation of scientific research results from prototype samples to products and to commodities, so as to achieve full application of scientific and technological achievements to the modernization cause". According to the latest "The Fourth National Survey of Scientific and Technological Workers" released by the Chinese Association of Science and Technology, among the scientific and technological workers who have engaged in R \& D in China in the past three years, only $38.1 \%$ of them were able to convert their scientific and technological achievements into products or use them in production and livelihood matters. The survey also reveals that $93.7 \%$ of scientific and technological workers who have published academic papers indicate that the main purpose of publishing papers is to meet the requirements for promotion and career advancement, and $90.4 \%$ of them indicate that their publications are to fulfill various assessment requirements. Ultimately, innovation should be conducive to industrial development and societal progress. If research endeavors only result in a pile of papers that are "filed and forgotten", it will not have any practical significance and contribution to the society.

The recent Sino-US trade friction is not just a simple trade war, it is broadly a science and technology war that affects the entire industrial chain from up- 
stream to downstream. The fundamental intention of the United States is not only to rectify trade imbalances, but also to significantly curb the development of China's high-tech enterprises. U.S. is utilizing Chinese Industries' disadvantageous position in global value chain to contain China's high-tech enterprise development. The recent punitive action against ZTE is a case in point. If China wants to counter that, it will need to adopt the strategy of "developing innovation chain around the industrial chain", and allow innovation to promote the transfer of Chinese enterprises from the "world factory" at the low-end of global value chain, to the "science and technology innovation center", which is at the high-end link of global value chain. In other words, China needs to let the industrial development "call" for more innovation, deepen the development dimension and breadth of innovation, and realize the mutual reinforcement of innovation chain and industrial chain.

In addition, to some leading industries with independent control capability, which are typically core technology advantage industries with independent intellectual property rights, China should also proactively adopt the development strategy of "deploying the industrial chain around innovation chain" and globally deploy the value chain led by these core industries. However, in the process of deploying the innovation chain around the high-tech-dominated industrial chain, China should also avoid or minimize the risk of crucial technology being controlled by others. This risk can be avoided or minimized by forming an independent innovation system that integrates design, research and development, production, and sales, and by being vigilant of technological advances of frontiers in the global arena so as to overcome the core technology barriers and avoid the danger of "supply cutoff" (such as the case of ZTE).

7) The relationship between technological innovation and military-civilian integration

Military-civilian coordination and integration is a strategic issue concerning the overall development of the national defense industry and the national economy. It is a fundamental way to achieve "wealthy nation and strong army" in the new era. To deal with and correctly handle the relationship between technological innovation and military-civilian integration is a major task in advancing the modernization of national governance system and capabilities in the new era, and is also an important driving force and strategic support for a country to achieve high-quality economic development.

National defense construction is utterly important and cannot be downplayed and even neglected. At present, China already has a somewhat established national defense force, and has basically formed a relatively independent and relatively complete national defense technology industrial system. However, there is still a large gap between China's national defense technology independent innovation capabilities and research and development capabilities compared with the world's leading powers. Persistence in obtaining combat effectiveness from scientific and technological innovation is still an inevitable trend in the future to strengthen the national defense industry. National defense science and technol- 
ogy innovation must not be content with the old path of "chasing from behind (being a follower)" and "looking into the mirror (being an imitator)." In the competition of the defense science and technology industry, whoever leads in technological innovation holds the military initiative, and whoever lags behind in defense science and technology innovation will be outstripped.

Since the 18th National Congress in 2014, the leadership of Chinese Communist Party has deeply grasped the global military development trend and the historical position of national defense forces, and has drawn a blueprint for technological innovation focusing on the realistic needs of building a world-class military that guarantees the successful realization of the Chinese dream and the dream of a strong military. The state has formed a military-civilian integration development strategy, delineated the internal logical relationship between technological innovation and national defense construction and mutual support, and also has pointed out the direction for deep integration of military, civilian, and scientific and technological collaboration to further seek compatible development of civilian sector with military sector, and compatible development of national defense construction with economic construction.

8) Relations between the state, society, scientific research circles and scientific and technological workers

The relationship between individual scientific and technological workers and the entire scientific research community, and the relationship between the scientific research community and the country and society, are both important subjects for deepening the high-quality development of scientific and technological innovation. We can't just stress that the scientific and technological workers should sit on the "cold bench" (devotion to research), and the entire scientific research community should work together to implement the central government's calling for generating significant research results and for creating a good research environment for the majority of science and technology workers. The state meanwhile should make efforts to accelerate the transformation of government functions, improve the construction of science and technology systems and mechanisms, and strengthen the protection and provision of scientific and technological innovation organizations and workers. In addition, the society should strive to create a social environment and a public opinion atmosphere that enhances respect for talents and respect for innovation accomplishments.

To encourage individual researchers to devote to research endeavors for the cause of national science and technology, it is necessary to continuously improve their working conditions and benefits. The starting and ending point of all economic and scientific work should always be to satisfy people's aspirations for a better life, including better life and reward for scientific research workers. Now, as scientific and technological innovation gradually enters the new stage of "running from behind, running side by side, and outrunning others", the working and living environment of scientific and technological personnel should be continuously improved. Specifically, it is necessary to concretely and effectively 
protect and improve the compensation of scientific and technological personnel, and to substantially reward (in fame, honor and wealth) those scientific and technological workers who have made real significant contributions. In addition, individual science and technology workers should also adhere to the bottom line of integrity, and advocate academic democracy. Researchers have to prevent and prohibit the "inner breeding" culture in the scientific research field, break all kinds of vested interest bonds and personal attachments, and work together to create a sound research environment for the entire scientific research community.

The state should continue to deepen the reform of institutional mechanisms in strategy, planning, policies and services, optimize the design of scientific research grant application, review and management mechanisms, and strengthen the organizational security of scientific and technological personnel in work and life. The key to building a good scientific research ecology and unleashing and extracting the full potential of science and technology workforce is to effectively reduce (if not remove) the financial, bureaucratic and other burdens on scientific researchers. The government also should prohibit and punish all kinds of scientific research activities that violate academic ethics and academic integrity. To combat the counterproductive academic atmosphere of exaggeration, opportunism, and seeking superfluous quick success, the state must eliminate the "inner connection phenomenon" in the scientific research circle, abolish the skewed dissertation-only, academic title-only, and award-only talent evaluation mechanism.

To achieve sustainable and high-quality development in scientific and technological innovation, in addition to government policies and legal environment, it also needs the strong support of a good social environment and a social atmosphere in which everyone respects, aspires and is capable of making technological innovations. There is need to create an atmosphere in which the whole society respects scientific talents and innovation, knowledge, and scientific research work, so that the love of science, the teaching of science, the study of science, and the use of science can permeate the entire society.

9) Relationship between government planning coordination and market mechanism adjustment

The relationship between government and market is a prominent contradiction in the process of deepening the development of scientific and technological innovation. To resolve this contradiction, it is necessary to persist in taking the market-oriented approach so that the market can play a decisive role in the allocation of scientific and technological resources. Under the premise of anchoring the development strategy to be innovation-driven, the government should give the market more independent and primary role to stimulate market innovation and competitive vitality, and build a new engine for development. In the process of building a country with strong science and technology power, if the government functions are misplaced, offside or absent, it will hinder the goal of reform. 
The key to promoting innovation to drive high-quality economic development is for the government to play a better role in stimulating the vitality of the main body of innovation.

By nature of the strong externalities of technological R \& D and innovation activities, "market failures" are bound to occur during the entire process of innovation. Therefore, it is not feasible to fully rely on market mechanisms to allocate science and technology resources. When market failures arise, it is crucial for the government to take initiative to lead and support science and technology innovation efforts. The roles government can play include being an advocate of innovation culture, a major investor in scientific research infrastructure, a facilitator for science and technology innovation, and a creator of an external innovation environment conducive to scientific research and technological development. Meanwhile, government support should be combined with market guidance to maximize the potential of technological innovation. To complement the market's decisive role in the allocation of scientific and technological resources, the government can assist and strengthen the guiding role of market mechanism in planning, rule and policy making, and setting strategic research directions to be more in line with the laws of market operation, so as to provide better institutional guarantee for further development of scientific and technological innovation, and to modernize macro-management capabilities. In addition, to give full play to the decisive role of the market in the allocation of scientific and technological resources, the government must be responsible for protecting the legitimate rights and interests of various entities involved in innovation activities, ensuring fair and free competition in the market, maintaining market order, and strengthening the moral and institutional foundation of the market economy. In sum, the government's role must be market friendly, market supporting, not market supplanting, so as to create and maintain a market environment that stimulates innovation.

10) The Relationship between internal innovation and external open cooperation in global context

By its nature, the issue about technological innovation needs to be treated and viewed in a global context. China's achievements in economic and technological development in the past 40 years are made possible under the conditions of opening up to the outside world. Likewise, in the future, China's goal of high-quality economic and scientific development can only be attained under the condition of a wider opening up and cooperation with the outside world. Although China has been attaching great importance to the opening up of science and technology, the strength and width of opening up in the technological sector is not on a par with the degree of opening up of the entire economic sector.

Chinese leadership needs to adapt to the new changes and trend of globalization and outside world, grasp the new requirements of domestic reform and development, and adopt a comprehensive innovation-led openness strategy that 
takes into account both domestic and foreign markets and uses both domestic and foreign resources. The construction of a country with strong science and technology must be planned and promoted from a global perspective, instead of doing it in isolation and blind action. There must be careful analysis, objective judgment, and wisdom to do the right "going out and bringing in" work of international cooperation and interactions.

On the one hand, China can turn from passive to active approach, taking initiative in promoting technological innovation and opening up. Following continuous improvement of overall economic strength and science and technology level, China has become a major science and technology power in the world, and is poised to play an active leading role in the opening up of science and technology field. On the other hand, China needs to rationally allocate and efficiently use scientific and technological innovation resources to improve the effectiveness of opening up. It is necessary to emphasize independent innovation in the process of opening up to the outside world, and use innovation to help transform the export structure from "quantity-oriented" to "quality-oriented", and form a new pattern of technology-led openness. "Quality-oriented export and import" trade structure is imperative to achieve high-quality economic development and technological innovation opening up, as the past "quantity-oriented" mode is no longer sustainable. To fulfill high-quality development, China should select to import core, cutting-edge technologies that the country lacks at present and in the future. At the same time, China should push for quality reform and technological innovation to circumvent the current problems of "great quantity but poor quality" in export structure. Through opening up China needs to achieve independent innovation, optimization of export structure, and formation of a "whole industry chain export" model of combining products, technologies and services. It is necessary to deepen international scientific and technological exchanges and cooperation, and actively integrate into the global scientific and technological innovation network. By strengthening the diversification and cooperation among global innovation institutions such as universities and research institutes, and by accelerating the flow of various scientific and technological resources, including scientific and technological information, technological trade, technological investment, and research and development cooperation. China can integrate innovation resources globally to greatly improve the effectiveness of science and technology plans and advance its scientific innovation capabilities.

What discussed above are the "Ten Major Relations" that must be addressed to resolve the structural contradiction on the supply side of technological innovation. In general, the foundation and main focus of the structural contradiction affecting the entire scientific and technological system lies on resolving the contradictions related to industry, academia, and research entities. The other contradiction affecting the entire science and technology system involves the relationship between government planning coordination and market mechanism 
adjustment. These contradictions that need to be addressed basically revolve around the reform of the scientific and technological innovation system and mechanism.

\section{Solving Structural Contradictions with the Supply of High-Quality Technological Innovation}

The world is made up of contradictions, and policymakers' task is to properly reconcile and resolve the contradictions. The main contradiction in China's current economic operation is still on the supply side of economic structure. Following and drawing from Zeng and $\mathrm{Wu}$ (2020), this article analyzes the structural contradictions in technological innovation, and points out the need to deal with the "Ten Major Relationships" to resolve the contradictions. Whether these relationships can be satisfactorily dealt with will directly affect whether the contradictions between the entire economic structure and system and the main social contradictions can be resolved properly.

Figure 1 displays the logical evolution path and trend of the structural contradictions of science and technology, economy and society. It can be seen that the structural characteristics of the main economic and social contradictions in China in the new era have determined that scientific and technological innovation, the engine and leitmotiv of sustainable growth, also exhibits the same attributes of structural contradictions on the supply side. Evidently, the main structural contradiction in China's current scientific and technological field lies in the shortage and inability of science and technology innovation supply to meet the demand for innovation results to construct an advanced science and technology country. Similarly, the main structural contradiction in Chinese economy lies in the supply shortage of high quality science and technology versus the demand for innovation-driven high quality development. Finally, the main structural contradiction existing in society lies in the contradiction between the people's ever-growing demand for a better life versus unbalanced and inadequate development.

Progressive Relationship Between Technological Innovation and Economic Development

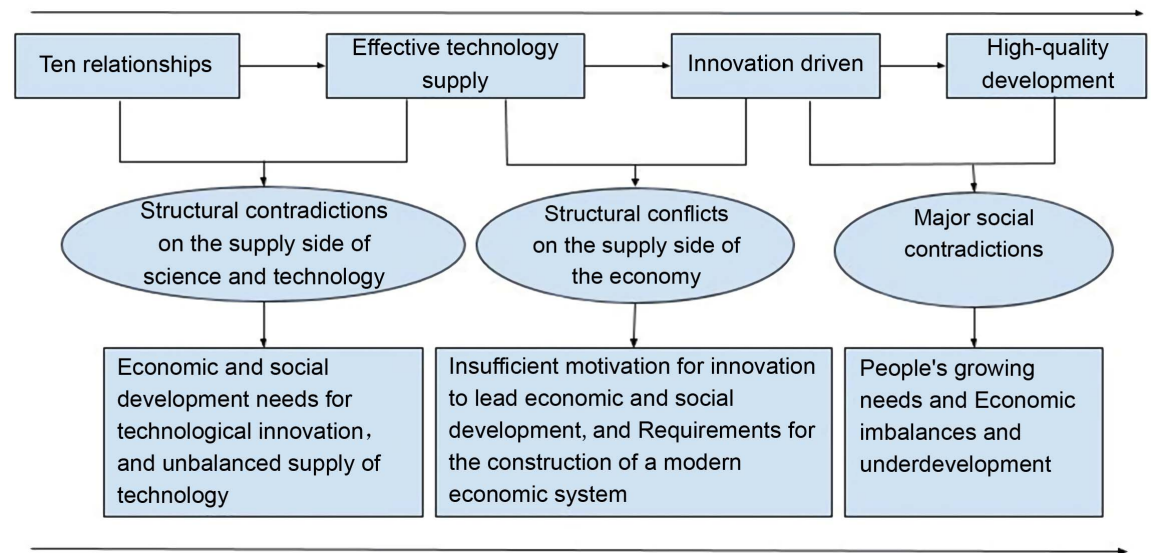

Figure 1. The evolution of structural contradictions in technology, economy, and society. 


\section{Conclusion}

In summary, based on the careful study of the logical evolutionary trend of the structural contradictions in China's science and technology, economy and society, it is not difficult to find that the crux of the economic and social development of the country mainly lies in the insufficient supply of high-quality science and technology. In response to this crux, this article proposes a reform path to solve the contradiction between economic and social conflicts with high-quality technology supply to solve the issue regarding high-quality science and technology supply hinges on solving the structural contradiction on the supply side of science and technology, which, in turn, hinges on reconciling and resolving the aforementioned "Ten Relationships". Therefore, to achieve high-quality technology supply, it is necessary to integrate the main entities of technology innovation including government, enterprises, colleges and universities, scientific research institutes, financial institutions, technology intermediaries, and end-users, etc., and to mobilize all contributing factors and resources including the state, society, and all domestic and foreign resources as well as all direct and indirect positive factors. Specifically, the following three points must be highlighted: First, reshape the power structure of technological innovation. Scientific and technological innovation requires the vast number of researchers to undertake independent original research to serve the country and people, and to advance the forefront of science and technology dedication and perseverance; second, strive to change conceptions and ideas, reform the system and incentive mechanisms, remove constraints, and remedy and shore up the weak points or shortcomings, that is: to change conceptions regarding traditional cultural, economic development and scientific and technological achievements ${ }^{6}$; to reform the science and technology management system and incentive mechanisms; to remove those administrative constraints, investment constraints, and institutional mechanism constraints that inhibit the vitality of research and development in science and technology; and to remedy or shore up the weak points or shortcomings such as the lack of core independent technologies, the low efficiency in transforming scientific and technological achievements, and insufficient motivations for innovation; third, clearly set development goals to significantly increase growth quantity, activate inventory or potentials, optimize structure and improve quality, that is: to increase the total amount of scientific and technological achievements and reserves; to activate and convert from inventory or reserve status of scientific and technological achievements into actual productivity; to optimize scientific and technological supply from the current demand and supply structure; and to provide high-quality technology supply to ultimately resolve the economic, social and technological structural contradictions.

${ }^{6}$ Yangfen Wu and Fanhua Zeng: Supply-side structural reform of technological innovation: A Perspective Based on the Effective Supply Hypothesis. Lournal of Jiangxi Normal University (Philosophy and Social Sciences Edition), 2019 (02): 123-131. 


\section{Acknowledgements}

We acknowledge the funding support from 1) Scientifically important project of Hubei Provincial Department of Science and Technology "Research on countermeasures to improve the supply capacity of science and technology innovation in Hubei Province" (No. 2017ADC002); 2) Hubei Provincial People's Government Intellectual Achievement Project "Research on High-quality Development Countermeasures of Science and Technology Innovation Supply Side of Hubei Province" (No. HBZZ-2018-04). We also gratefully acknowledge Journal of Yunnan University of Finance and Economics for permission to draw some relevant arguments and materials from Zeng and $\mathrm{Wu}$ (2020) published in Chinese in that journal, Issue No. 3, 2020, pp. 11-19.

\section{Conflicts of Interest}

The authors declare no conflicts of interest regarding the publication of this paper.

\section{References}

Bush, V. (2004). Science: The Endless Frontier (p. 64).

Sun, Z., \& Xu, X. L. (2017). Frontier Technology Gaps and Scientific Research Innovation Effect-Basic Research and Applied Research: Who Played a More Important Role. China Industrial Economy, No. 3, 5-23.

Wu, Y. F., \& Zeng, F. H. (2019). Supply-Side Structural Reform of Technological Innovation: A Perspective Based on the Effective Supply Hypothesis. Journal of Jiangxi Normal University (Philosophy and Social Sciences Edition), No. 2, 123-131.

Xi, J. P. (2018). Speech at the 19th Academician Conference of the Chinese Academy of Sciences and the 14th Academician Conference of the Chinese Academy of Engineering. People's Daily, 2018-05-29.

Ye, X. S., \& Liu, J. (2018). Heterogeneous R \& D, Government Support, and China's National Borders of Scientific and Technological Innovation. Economic Research, No. 9, 116-132.

Zeng, F., \& Wu, Y. (2020). Policy Prescriptions to Achieve High Quality Development of the Supply Side of Scientific and Technological Innovation. Journal of Yunnan University of Finance and Economics, No. 3, 11-19. 